\title{
Corrosion protection of magnesium alloy by PEO-coatings containing sodium oleate
}

\section{A.A. Chirkunov, ${ }^{1 *}$ A.G. Rakoch, ${ }^{2}$ E.V. Monakhova, ${ }^{2}$ A.A. Gladkova, ${ }^{2}$ Z.V. Khabibullina, ${ }^{2}$ V.A. Ogorodnikova, ${ }^{1}$ M. Serdechnova, ${ }^{3}$ C. Blawert, ${ }^{3}$ Yu.I. Kuznetsov ${ }^{1}$ and M.L. Zheludkevich ${ }^{3,4}$}

${ }^{1}$ A.N. Frumkin Institute of Physical Chemistry and Electrochemistry, Russian Academy of Sciences, Leninsky pr. 31, 119071 Moscow, Russian Federation

${ }^{2}$ Department of Metal Protection and Surface Treatment, National University of Science and Technology "MISiS”, Leninsky pr., 119049 Moscow, Russian Federation ${ }^{3}$ Helmholtz-Zentrum Geesthacht, Centre for Materials and Coastal Research GmbH, MaxPlank Str.1, 21502, Geesthacht, Germany

${ }^{4}$ Faculty of Engineering, Kiel University, Kaiserstrasse 2, 24143, Kiel, Germany

*E-mail: chirkunov@inbox.ru

\begin{abstract}
The kinetics of plasma-electrolytic oxidation (PEO) coating growth on AZ31 alloy in an alkaline-phosphate-aluminate electrolyte was studied. The structure, elemental composition and corrosion resistance of obtained PEO coatings were studied as a function of thickness. It was established that formation of the coating layers takes place in the following sequence: anodic, external and internal layers. Their formation occurs due to: 1) dielectric layer formation due to anodic conversion of surface; 2) ignition of powerful microdischarges in the transversal pores of the initially formed coating, forming the main part of its outer layer in case of increasing duration of the PEO process; 3 ) etching of magnesium alloy as a result of electrolyte penetration through the transversal pores to the metal substrate, followed by its anodizing; 4) ignition of microdischarges under the coatings outer layer, leading to formation of an inner layer. Existence of the coating inner layer causes a significant increase in corrosion resistance; however, it is still insufficient for long-lasting standalone corrosion protection. It was shown that sodium oleate ( $\mathrm{SOl}$ ) is the best inhibitor for the AZ31 substrate, therefore it was selected for impregnating PEO coatings. Impregnation of the coatings in $10 \mathrm{mM} \mathrm{SOl}$ solution increases their protective ability. Corrosion tests of PEO coated AZ31 samples in a climate chamber showed that the effect of impregnating is most pronounced for thin PEO coatings $(20 \mu \mathrm{m})$. Under more corrosive conditions of salt spray test, impregnating the PEO coating with $\mathrm{SOl}$ increased the time until the appearance of the first corrosion marks. It also significantly slowed down the development of the corrosion marks compared with the samples coated by PEO without impregnation.
\end{abstract}

Keywords: magnesium alloy, plasma electrolytic oxidation, corrosion protection, corrosion inhibitor. 


\section{Introduction}

Magnesium alloys are widely used in transport and 3C industries due to their low density, high specific strength, ability to absorb shock energy and vibrations. However, due to their low corrosion resistance in a wide range of environments they often need protective coatings to improve wear and corrosion resistance.

The most promising method for synthesizing protective coatings on magnesium alloys is plasma electrolytic oxidation (PEO), which has been successfully used to protect aluminum alloys [1-3]. However, PEO coatings formed on magnesium alloys are highly porous [4-6]. Moreover, they are two-layered coatings. Their outer layers, which are the thickest, are more porous than the inner ones [6].

Numerous attempts such as modifying treatment parameters or introducing various micro- and nanoparticles into electrolytes [7-17] have been made to increase corrosion resistance of PEO coatings. However, none of them was successful.

The PEO process of magnesium alloys is a multi-stage process. For example, Sobrinho et al. [18] suggested that the PEO process of AZ31B is a four-stage process. At the first stage, anodizing process takes place, which is replaced by local etching of the formed anodic film (second stage). At the 3rd stage, pores are partially filled up, which causes subsequent intensive coating formation. At the last stage two types of microdischarges appear on the working electrode surface. The authors [18] do not take into account microbreakdowns of a gas-vapor phase, formed in the coating pores, which appear as a result of Joule heat release, oxygen and hydrogen formation during anodic and cathodic half-periods, respectively $[1-3,19,20]$.

Intensive dissolution of the metal substrate in hot concentrated electrolytes is also not taken into account during PEO of magnesium alloys. Etching may cause generation of longitudinal pores along the metal substrate/coating interface and promote PEO process under the initially formed porous layer [21].

It is likely that knowledge about the time when the denser inner layer starts to grow allows to increase corrosion resistance of PEO coatings on magnesium alloys.

Another way to increase the protective properties of PEO-coatings is the impregnation with corrosion inhibitors (CIs). Some chelating agents can be used as effective CIs. According to [22], 2-hydroxy-4-methoxy-acetophenone, which slows down the anodic dissolution and corrosion of AZ31D magnesium alloy, is able to form a chelate complex with magnesium hydroxide. Polarization measurements and electrochemical impedance spectroscopy (EIS) showed that the maximum protection efficiency is achieved at a concentration of acetophenone $C_{\text {in }}=50 \mathrm{ppm}(Z=90 \%$ and $88 \%$, respectively). With a further increase in $C_{\text {in }}$, the $Z$ value decreases, this is consistent with the results of weightloss measurement in $0.05 \% \mathrm{NaCl}$. 
Among the chelating agents, the most well-known is 8-hydroxyquinoline (8-HQ) which effectively protects AZ91D alloy and is able to give coatings self-healing properties [23]. The authors of [24] successfully modified LDH coatings on AZ91 by impregnating them in an 8-HQ alkaline solution. AZ91D alloy was protected for 30 days even in $3.5 \%$ $\mathrm{NaCl}$ (in contrast to LDH without CI). Gnedenkov et al. [25] showed that 8-HQ can be used to increase the corrosion resistance of PEO coatings on MA8 alloy. The PEO coating impregnated in 8-HQ solution for $120 \mathrm{~min}$, demonstrates a good protection in $3 \% \mathrm{NaCl}$, reducing the corrosion current density by 3 orders of magnitude and increasing the impedance module by two orders of magnitude compared to the uncoated samples. Moreover, the corrosion rate for samples with PEO coating impregnated by 8 -HQ is $17 \%$ lower than for samples without impregnation.

Lamaka et al [26] analyzed the effectiveness of 151 compounds as CI for 6 magnesium alloys (AZ31, AZ91, AM50, WE43, ZE41 and Elektron 21) and 3 magnesium samples of various purity degrees. Screening showed that the effectiveness of CIs strongly depends on the composition of the alloy. The sodium salts of pyridinedicarboxylic and salicylic acid derivatives have proven to be the most universal CI. The authors attribute their high inhibition activity to the ability to form stable complexes with iron cations. In [27], it was shown that PEO coating infiltrated by sodium salt of 3 -methyl salicylate and covered with an epoxy layer effectively suppresses local corrosion after its mechanical damage. This is due to the presence of CI molecules in the pores, and their accumulation in the area of the defect.

Salts of phosphonic, carboxylic and phosphoric esters acids containing hydrophobic alkyls are also known as CIs for magnesium and its alloys [28-32]. Salts of non-toxic higher acids, in particular sodium oleate, oleoyl sarcosinate, etc., deserve special attention.

In this regard, two concepts were combined in the present study to obtain protective active coatings on AZ31 magnesium alloy. By understanding and optimizing the growth mechanism, a dense inner layer of PEO coating is produced while the outer porous layer is impregnated by an aqueous solution of carboxylate based CI.

\section{Experimental}

PEO coatings were applied on plates $(30 \times 25 \times 2 \mathrm{~mm})$ of magnesium alloy AZ31. The concentrations (wt.\%) of the main alloying elements determined with a SPAS-02 spectrometer (Russia) are given in Table 1.

Table 1. Concentration (wt.\%) of main alloying elements in AZ31 alloy.

\begin{tabular}{cccccccc}
\hline $\mathbf{A l}$ & $\mathbf{Z n}$ & $\mathbf{M n}$ & $\mathbf{B e}$ & $\mathbf{F e}$ & $\mathbf{C u}$ & $\mathbf{N i}$ & $\mathbf{S i}$ \\
\hline 3.03 & 1.00 & 0.28 & 0.0005 & 0.0029 & 0.0007 & 0.0010 & 0.021 \\
\hline
\end{tabular}


Sodium oleate (SOl), sodium oleoyl sarcosinate (SOS), sodium linolenate (SLin), sodium salt of 3-amino-1,2,4 triazole-5-carboxylic acid (SATC), 8-hydroxyquinoline (8$\mathrm{HQ}$ ), mixtures of $8 \mathrm{mM} \mathrm{SOl}+8 \mathrm{mM}$ sodium flufenamate (IFKhAN-25F) and $13 \mathrm{mM} \mathrm{SOl}+$ $3 \mathrm{mM} 8$-HQ were studied as CIs. Working solutions of $16 \mathrm{mM}$ of all CIs, except for 8-HQ, were prepared by dissolving them in distilled water or in testing solutions under stirring for $30 \mathrm{~min}$. Since 8 -HQ has a low solubility in water (a total of $3.65 \mathrm{mM}$ or $0.53 \mathrm{~g} / \mathrm{L}$ ), its $16 \mathrm{mM}$ solution was prepared using ethanol as a solvent. To obtain the sodium salts, the solutions of SOS, SLin, SATC and IFKhAN-25F were neutralized with $\mathrm{NaOH}$.

AZ31 samples were ground on emery papers from 240 to 1000 grit and degreased with acetone. Passivated layers on AZ31 alloy were obtained by immersion in CI solutions for $10 \mathrm{~min}$ at a temperature of $20 \pm 2^{\circ} \mathrm{C}$, followed by drying in air for 1 hour.

Polarization measurements were performed in a glass cell with separated electrode spaces using an IPC-ProMF potentiostat. The potentials of $\mathrm{Mg}(E)$ were measured relative to a silver chloride electrode and recalculated to the normal hydrogen scale. The auxiliary electrode was Pt. Borate buffer ( $\mathrm{pH} 9.2)$ containing $\mathrm{NaCl}(1.0 ; 10$ and $100 \mathrm{mM})$ and aqueous $\mathrm{NaCl}$ solutions ( 0.3 and $3.0 \mathrm{wt} . \%)$ were used as the test solutions in the electrochemical studies.

Tests with periodic moisture condensation were carried out in a KTW-0.1-002 climate chamber (Russia). The chamber worked in a cyclic mode. Initially the samples were exposed to air at $T=40 \pm 2^{\circ} \mathrm{C}$ and a relative humidity of $98-100 \%$ for 7 hours. Then the chamber was switched to the cooling mode and for the next 17 hours the samples were exposed at $T=20 \pm 2{ }^{\circ} \mathrm{C}$ and a relative humidity of $98-100 \%$, which provides moisture condensation on the samples. During the tests, the samples were inspected every 1 hour to determine the time of occurrence of first corrosion marks $\left(\tau_{\text {cor }}\right)$.

The capacity-based PEO equipment, which was used to perform the PEO treatments was described in more details in [33].

An aqueous solution based on distilled water and containing $2 \mathrm{~g} / \mathrm{l}$ of $\mathrm{NaOH}, 3 \mathrm{~g} / \mathrm{l}$ $\mathrm{Na}_{6} \mathrm{P}_{6} \mathrm{O}_{18}$, and $10 \mathrm{~g} / \mathrm{l} \mathrm{NaAlO}_{2}$ was prepared and the electrolyte volume was kept at approximately $5 \mathrm{~L}$. An alternating current was passed between the electrodes with a specified current density of $15 \mathrm{~A} / \mathrm{dm}^{2}$, which is supposed to be one of the most used current densities for producing protective coatings on magnesium alloys [4]. The current was stabilized by its average rectified value.

A Canon 550D digital camera was used for photographic recording of the anodic microdischarges during PEO treatment of AZ31. The camera was securely mounted on a stand. The exposure time was $10 \mathrm{~ms}$.

A Fischer Dual Scope FNP10 thickness gauge was used to estimate coating thicknesses. Prior to measurements the gauge was calibrated using calibration samples and the alloy surface. At least 12 thickness measurements were carried out at different areas of the coating, and then the average thickness and standard deviations were determined. 
Micrographs of the surface and cross sections were obtained using a Tescan VEGA3 SB scanning electron microscope, and the concentrations of the elements in the various coating layers were determined using a supplement to the EDX spectroscope.

A Rigaku Ultima IV X-ray diffractometer with monochromated $\mathrm{Cu} \mathrm{K} \alpha$-radiation was used for X-ray phase determination.

Corrosion resistance of the coatings was evaluated using immersion tests in $3 \mathrm{wt} \%$ $\mathrm{NaCl}$ solution at room temperature with further observations of the first hydrogen bubble releases and first visible pit appearance, as well as additional tests in Weiss SC/KWT 450 salt spray chamber (SSC). A $5 \% \mathrm{NaCl}(\mathrm{pH} \mathrm{6.9)}$ saline solution was used in the SSC. The chamber worked continuously in a cyclic mode: 15 minutes of saline spraying, then the spraying was stopped for 45 minutes, then the cycle was repeated. The tests were carried out at $t=35^{\circ} \mathrm{C}$ and a relative humidity of $95-100 \%$. Inspection of the samples was performed 3 times a day to establish the time of occurrence of first corrosion marks $\left(\tau_{\text {cor }}\right)$.

All results given in this study are calculated from a set of experimental data after at least five reproductions of each measurement.

\section{Results and discussion}

\section{Selection of corrosion inhibitor}

The primary selection of CI was carried out using AZ31 without PEO coatings. The CI containing passive films were produced by immersion of the alloy into various CI solutions. The protective effect of these CI containing films was studied afterwards in borate buffer solution ( $\mathrm{pH}$ 9.2) containing $1 \mathrm{mM} \mathrm{NaCl}$ (Figure 1). For this purpose, immersion samples were dried, then placed into the cell and the anodic polarization was immediately started from the open circuit potential $\left(E_{\text {ocp }}\right)$.

As can be seen from Figure 1, when the bare AZ31 electrode is immersed in the buffer solution, active dissolution of magnesium is observed $\left(E_{\text {ocp }}=-1.52 \mathrm{~V}\right)$. Films formed in aqueous solutions of $16 \mathrm{mM}$ SLin and SATC only shift the initial potential by 66 and $104 \mathrm{mV}$ in the anodic direction, respectively. Treatment in a $16 \mathrm{mM}$ ethanol solution of 8-HQ increases $E_{\text {ocp }}$ by $0.124 \mathrm{~V}$; there is no region with low current densities on the anodic polarization curve. The SOS film stimulates anodic dissolution, shifting $E_{\text {ocp }}$ by $39 \mathrm{mV}$ in the cathodic direction.

The best performance was obtained after passivation of the electrode in a $16 \mathrm{mM} \mathrm{SOl}$ solution. A passivity region and the highest increase in $E_{\text {ocp }}(-1.28 \mathrm{~V})$ can be observed on the anodic polarization curve. The mixed compositions IFKhAN 25F as well as $13 \mathrm{mM}$ $\mathrm{SOl}+3 \mathrm{mM} 8$-HQ are slightly less effective than the SOl itself in shifting the OCP $(-1.44 \mathrm{~V})$, but extended regions with reduced anodic dissolution are also present on the polarization curves. The adsorption film of the IFKhAN-25F mixture provides a greater shift of $E_{\text {ocp }}$ than the mixture of SOl with 8-HQ (149 and $81 \mathrm{mV}$, respectively). However, 
the region of reduced anodic dissolution for $13 \mathrm{mM} \mathrm{SOl}+3 \mathrm{mM} \mathrm{8-HQ}$ is more extended than in the case of IFKhAN-25F.

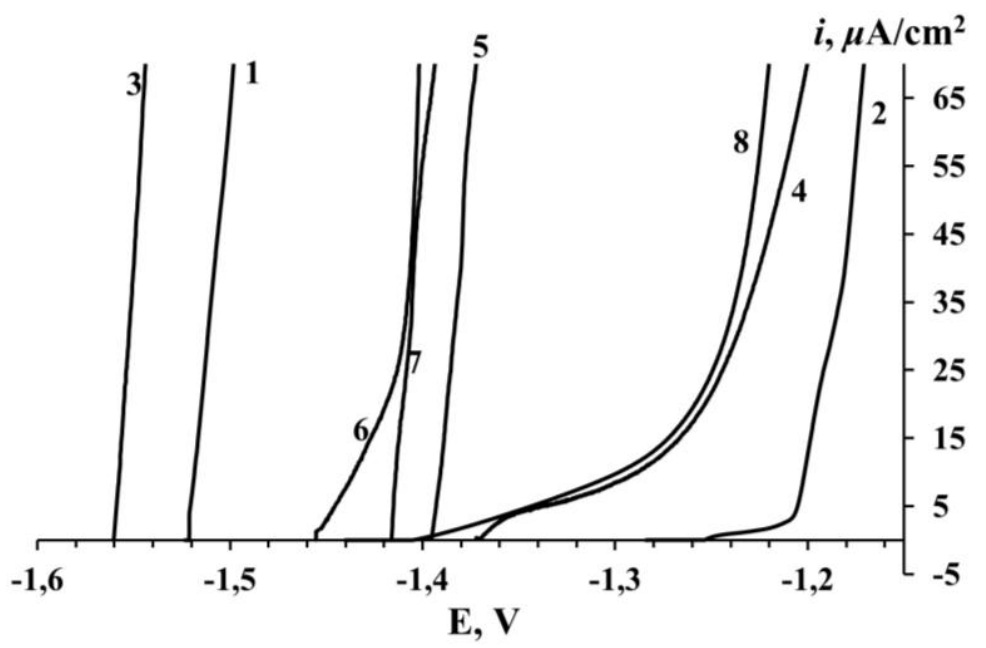

Figure 1. Anodic polarization curves of AZ31 alloy in a borate buffer with a $\mathrm{pH}$ of 9.2 containing $1 \mathrm{mM} \mathrm{NaCl}$ : bare AZ31 without preliminary CI adsorption (1) and after immersion into $16 \mathrm{mM} \mathrm{CI}$ solutions for $10 \mathrm{~min}$ and drying in air: $2-\mathrm{SOl}, 3$ - SOS, 4 - IFKhAN-25F, 5 - 8-HQ, 6 - SLin, 7 - SATC, 8 - mixture of $13 \mathrm{mM} \mathrm{SOl+} 3 \mathrm{mM} 8$-HQ.

For the best performing CI solution with $\mathrm{SOl}$ the influence of $\mathrm{Cl}^{-}$concentration was checked. Figure 2 shows the anodic polarization curves of AZ31 in borate buffer of $\mathrm{pH} 9.2$ containing $16 \mathrm{mM} \mathrm{SOl}$ with addition of $\mathrm{NaCl}$ with concentrations of 1,10 , and $100 \mathrm{mM}$ (Figure 2). The electrode was immersed in the solution for 5 min prior to polarization with a sweep rate of $0.2 \mathrm{mV} / \mathrm{s}$ starting from the OCP.

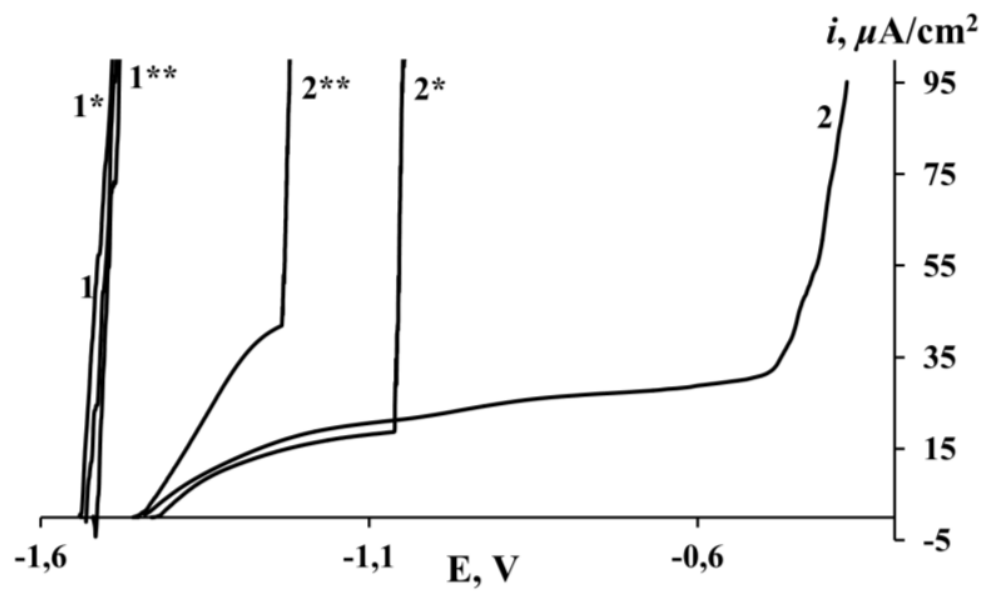

Figure 2. Anodic polarization curves of AZ31 alloy in borate buffer $\mathrm{pH} 9.2$ without $\mathrm{CI}$ (1) and with $16 \mathrm{mM} \mathrm{SOl} \mathrm{(2)} \mathrm{in} \mathrm{the} \mathrm{presence} \mathrm{of} \mathrm{NaCl}$ with a concentration of $1 \mathrm{mM}$ - "without an upper index"; $10 \mathrm{mM}$ - “*”; and $100 \mathrm{mM}$ - “**”. 
The concentration of $\mathrm{NaCl}$ in the absence of the CI does not affect the anodic dissolution of the AZ31 alloy too much. However, in the presence of SOl, with an increase in $C_{\mathrm{NaCl}}$, the "pseudo"-passive region with reduced anodic dissolution decreases significantly, and the retardation of pitting is reduced as well by increasing $\mathrm{Cl}^{-}$ concentration: $E_{\text {pit }}^{\text {in }}=1.04,0.46$ and $0.26 \mathrm{~V}$, respectively.

As can be seen in Figure 3, even in the presence of $3 \% \mathrm{NaCl}$, the addition of $16 \mathrm{mM}$ $\mathrm{SOl}$ reduces the anodic current density. An increase in the concentration of SOl almost does not change $E_{\text {ocp}}$; however, a significant increase in $E_{\text {pit }}$ is observed on the anodic polarization curves, and, as a consequence, the onset of pitting is retarded.

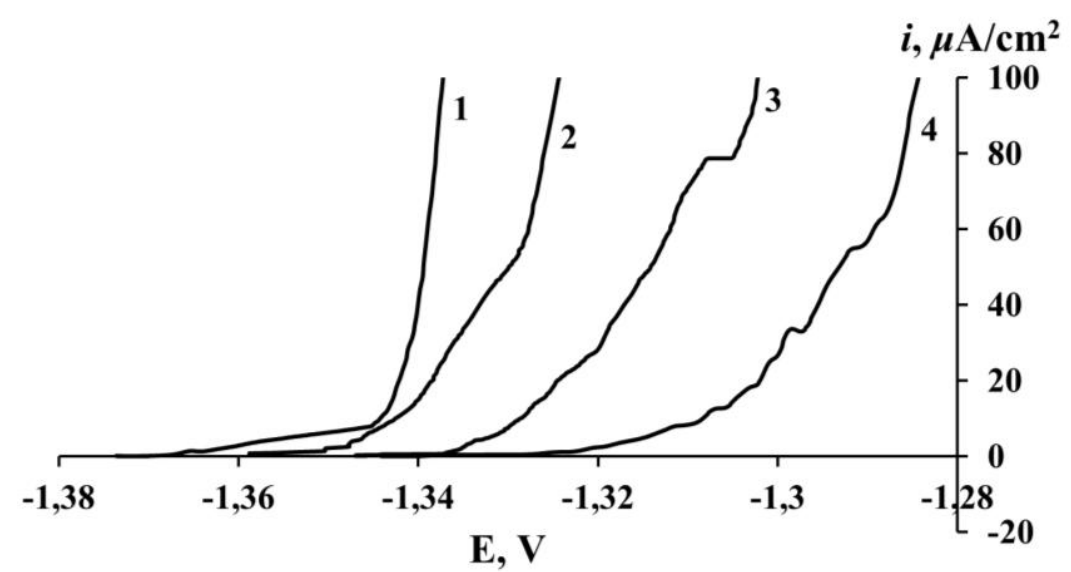

Figure 3. Anodic polarization curves of AZ31 alloy in $3 \% \mathrm{NaCl}$ without $\mathrm{CI}(1)$ and after adding $\mathrm{SOl}$ in different concentrations: $2-16 \mathrm{mM}, 3-50 \mathrm{mM}, 4-100 \mathrm{mM}$.

According to data obtained earlier in $[30,31]$ on $\mathrm{Mg} 90$ alloy $(99.9 \%$ of $\mathrm{Mg}$ ) during periodic condensation of moisture, corrosion damages appear on it after $0.5-1$ hours. The protection efficiency of this alloy with the CIs increases in the following order: SLin < SOS < SOl (the $\tau_{\text {cor }}$ is $4 ; 8$ and $18-20 \mathrm{~h}$, respectively). The results of the same corrosion tests for the AZ31 alloy (Table 2) showed that it is somewhat more corrosion resistant, and $\mathrm{SOl}$ is the most effective CI for it.

SOl was also the best option to protect $\mathrm{Mg} 90$ alloy preoxidized in $5 \mathrm{M} \mathrm{NaOH}$, thus covered with a thin oxide-hydroxide film $(\sim 80 \mathrm{~nm})$ [31]. According to electrochemical and corrosion data, the use of SOl solutions for impregnating PEO coatings on AZ31 appears to be the most appropriate.

\section{PEO of AZ31 in alkali-aluminate electrolyte}

The kinetics of PEO coating growth on AZ31 alloy (Figure 4) in an alkali-phosphatealuminate electrolyte can be described by linear laws. During PEO in the time range from 0 to $12.5 \mathrm{~min}$ : the coating thickness $h$ can be determined by $h=1.98 \cdot t$ (the $1^{\text {st }}$ linear law), and in the range of $12.5-32.5 \mathrm{~min}$ : by $h=24.7+1.6 \cdot(t-12.5)$ (the $2^{\text {nd }}$ linear law). 
Table 2. Results of climate chamber corrosion tests of samples from AZ31 alloy pretreated in CI solutions.

\begin{tabular}{ccc}
\hline No. & The composition of the passivating solution & $\boldsymbol{\tau}_{\text {cor. }} \mathbf{h}$ \\
\hline 1 & Without inhibitor (blank) & $1.5-2$ \\
2 & 16 mM SOl & $23-27$ \\
3 & 10 mM SOl & 20 \\
4 & 16 mM SOS & 9 \\
5 & 16 mM IFKhAN 25F & 18,5 \\
6 & 16 mM 8-HQ & 5 \\
7 & 16 mM SLin & 6 \\
8 & 16 mM SATC & $<1$ \\
\hline
\end{tabular}

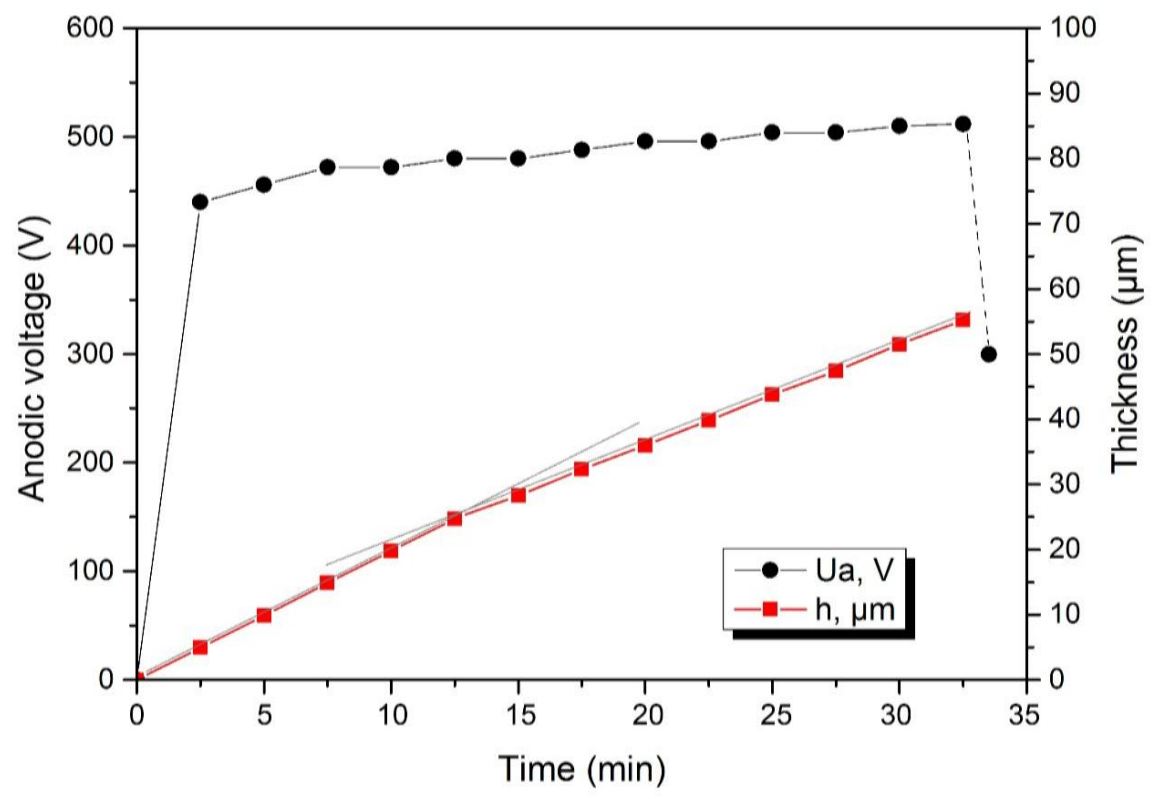

Figure 4. Kinetics of the coating average thickness growth and evolution of voltage as function of time during PEO treatment of AZ31 in an alkali-phosphate-aluminate electrolyte.

During PEO of magnesium alloy in alkali-phosphate-aluminate electrolyte the type of micro-discharges, igniting on the working electrode surface, is changing visually with increasing treatment time (Figure 5). After a short time interval (not more than $40 \mathrm{~s}$ ) numerous anodic microdischarges appear on the sample surface; their intensity increases with exposure time up to $12.5 \mathrm{~min}$. This is typical for PEO treatment of all light metals [16]. Occurrence of this type of microdischarges corresponds to kinetics described by the $1^{\text {st }}$ linear law of coating growth. 
It can be seen from the micrographs (Figure 6a) that during this time period a generation of longitudinal pores close to the metal substrate is taking place.

However, if the treatment time increases to more than $12.5 \mathrm{~min}$, small faint microdischarges appear on the working electrode surface simultaneously with the single powerful microdischarges (Figure 5a). When the treatment time exceeds 25 min, the bright more powerful anodic microdischarges disappear and just faint ones ignite (Figure 5b). With the appearance of the second type of discharges the linear law of the coating growth changes (Figure 4) and the inner layer starts to grow.

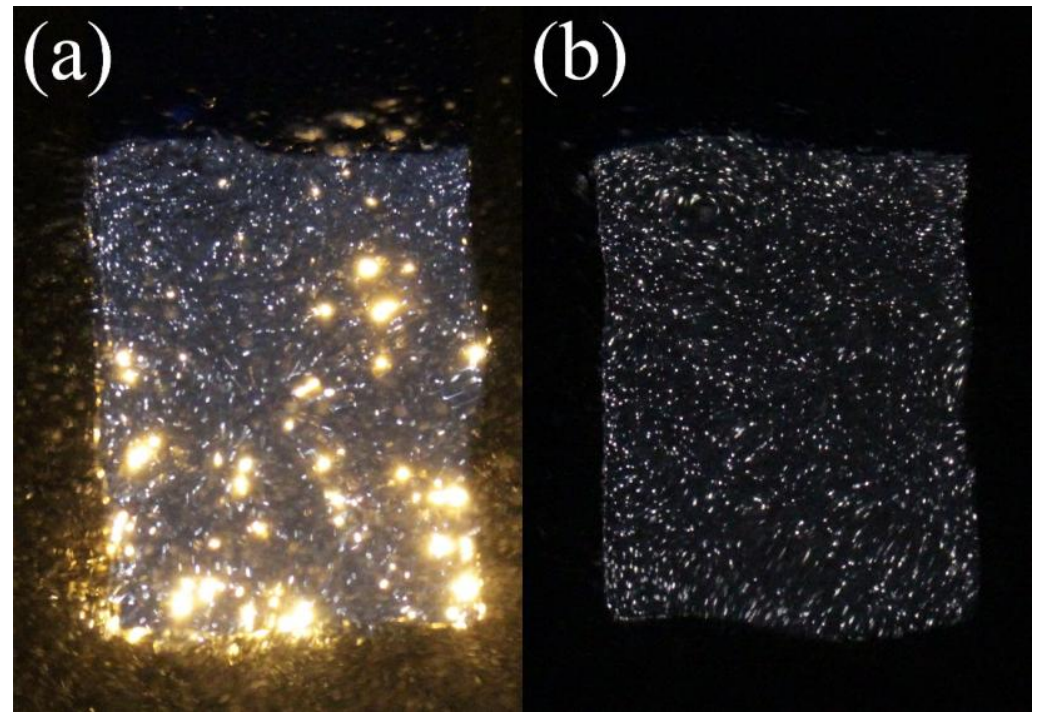

Figure 5. Appearance of microdischarges for treatment times longer than 12.5 (a) and 25 (b) min of PEO treatment of AZ31 alloy in alkali-phosphate-aluminate electrolyte.

The finally synthesized coating after $32 \mathrm{~min}$ is three-layered (Figure 6b), consisting of anodic, inner and outer layers.
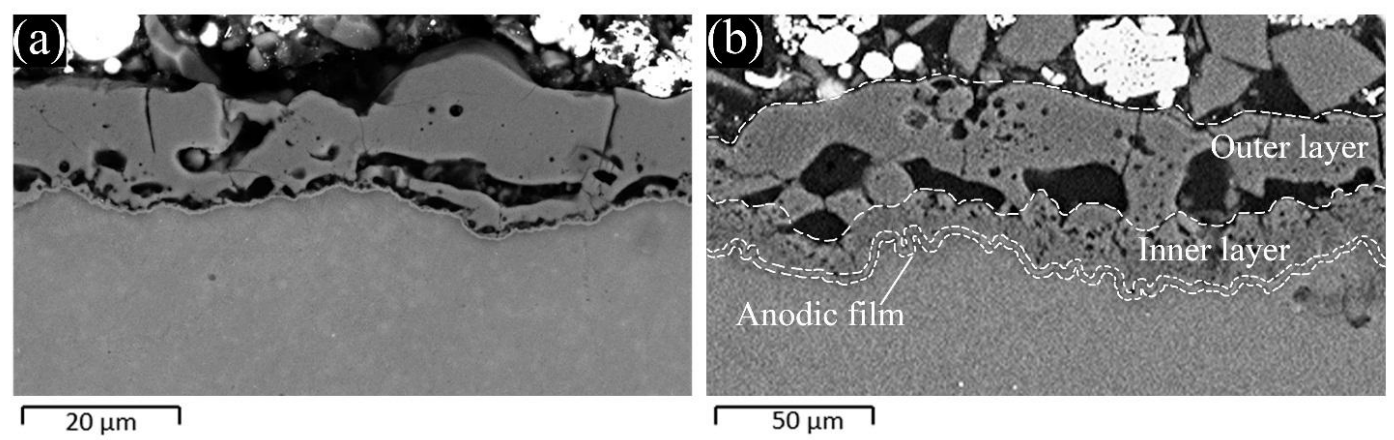

Figure 6. SEM micrographs of cross-section morphology of coatings with various thicknesses: a) $18.5 \pm 3.5 \mu \mathrm{m}$; b) $54.5 \pm 5.0 \mu \mathrm{m}$ synthesized on AZ31 after PEO treatment in an alkali-phosphate-aluminate electrolyte. 
The outer layer is composed of $\mathrm{MgO}, \mathrm{Mg}_{3}\left(\mathrm{PO}_{4}\right)_{2}$ and $\mathrm{MgAl}_{2} \mathrm{O}_{4}$ while the inner layer mainly consists of $\mathrm{MgO}$ (Figures 7, 8, Table 3).

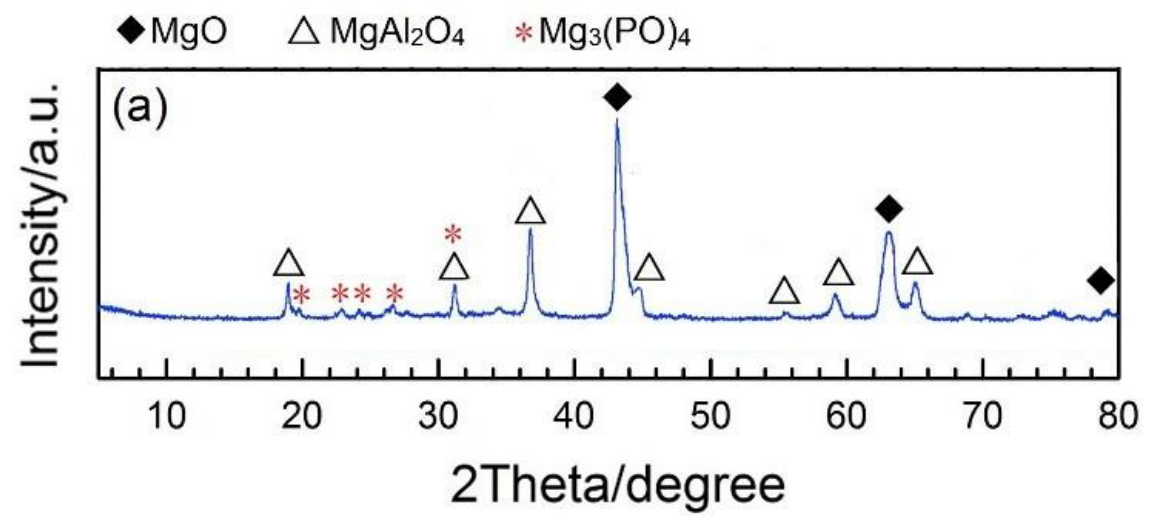

Figure 7. XRD patterns of the coatings obtained during PEO of AZ31 alloy in an alkaliphosphate-aluminate electrolyte; the average coating thickness is $55 \mu \mathrm{m}$.

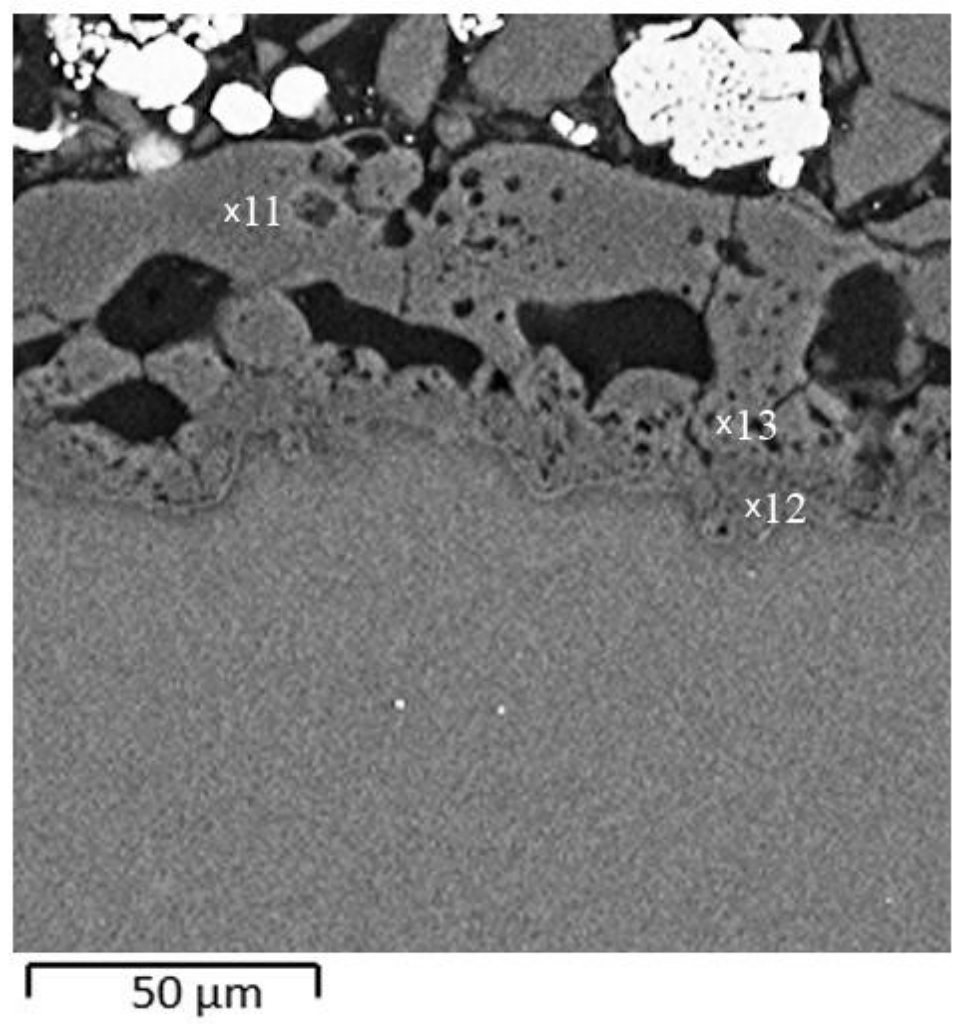

Figure 8. SEM micrograph of cross section morphology of coating obtained during PEO of AZ31in an alkali-phosphate-aluminate electrolyte; the average coating thickness is $54.5 \mu \mathrm{m}$. 
Table 3. Elemental composition of PEO coatings obtained on AZ31 (locations of analysis according to Figure 8).

\begin{tabular}{cccc}
\hline \multirow{2}{*}{ Element } & \multicolumn{3}{c}{ Composition, wt. \% } \\
\cline { 2 - 4 } & Point 11 & Point 12 & Point 13 \\
\hline $\mathrm{Mg}$ & 37.6 & 51.5 & 52.6 \\
$\mathrm{O}$ & 43.7 & 46.1 & 47.0 \\
$\mathrm{Al}$ & 14.5 & 1.5 & 0.4 \\
$\mathrm{P}$ & 4.2 & 0.9 & - \\
\hline
\end{tabular}

It is well-known [18, 34-37] that the coating growth on magnesium alloys during PEO treatment is multi-staged. The same was observed here for the PEO processing of AZ31 in an alkali-phosphate-aluminate electrolyte (Figure 5, 6).

At the first stage anodizing and significant increase of the anodic voltage take place (Figure 4). Then at the second stage the coating growth mainly occurs due to the ignition of anodic plasma microdischarges in transversal pores which reach the metal substrate. These microdischarges promote heating of adjacent coating areas. In this case similar to PEO of aluminum and titanium alloys oxidation of the metal substrate, electrolysis of anions on the working electrode surface and plasma-thermochemical treatment of the coatings occur [1-3].

The electrolyte penetrates towards the metal base through the transversal pores of the coating. The $\mathrm{OH}^{-}$ion concentration in the electrolyte, filling the coating pores, increases due to cathodic reactions which lead to formation of hydroxide ions.

In the time intervals when plasma microdischarges don't occur during PEO, the following processes can take place: 1) at temperatures above $60^{\circ} \mathrm{C} \mathrm{Mg}$ and $\mathrm{MgO}$ are dissolving (at higher rates at locations adjacent to intermetallics [21]). In the metal substrate-coating interface region, generation of longitudinal pores starts; 2) anodizing takes place with formation of $\mathrm{MgO}$ on the metal substrate and its simultaneous dissolution.

This is the reason why PEO coatings with thicknesses up to $20 \mu \mathrm{m}$ synthesized on magnesium alloy in various electrolytes are highly-porous $[6,7,39]$.

Further PEO treatment of AZ31 increases the level of filling-up of pores. The probability of occurrence of two independent discharge processes is increasing (Figure 7a). PEO also starts under the coating outer layer due to increase of the energy released by microdischarges in numerous pores of the anodic film. Furthermore, formation of large microvoids takes place in transversal twisting pores (Figure 7a). The latter is probably caused by ignition of powerful microdischarges in narrow places or at kinks of those pores (Figure 7a) due to filling-up with the gas-vapor phase containing large amounts of anodic oxygen and cathodic hydrogen. Thus, voids are generated in the coating outer layer (Figures 6b,9b). When microdischarges start to occur at the bottom of large pores 
(Figure 7b), they can cause microdiscontinuity of melted coating parts adjacent to these breakdowns [6].

A large amount of gas is released, as well in ionized form, causing formation of large microdefects on the surface $[4,6]$.

The microdischarges, which appear under the coating outer layer, cause oxidation of the metal substrate. The melted magnesium oxide remains in the inner layer formed on the anodic film (Figure 6b).

The electrolysis of tetrahydroxoaluminate anions does not occur on the surface of the coating inner layer due to a large number of micro-discharges igniting in the pores of these layers, thus the gas-vapor phase covers a large part of its surface. This is the reason for the presence of large amount of $\mathrm{MgO}$ in the coating inner layer (Figure 6, 7, Table 3).

At this stage two types of microdischarges faint small ones and bright larger ones appear on surface of the working electrode (Figure 5a).

If the coating thickness exceeds $45.7 \pm 5 \mu \mathrm{m}$, only faint microdischarges appear and the powerful ones disappear (Figure 5b). Probably, the increase in temperature in the coating is the reason for this. Thus, the height of the gas-vapor phase in transversal pores, including those having large voids, increases. At the $4^{\text {th }}$ stage, PEO takes place only in the microvoids of the inner layer (Figure 9c).

The abovementioned mechanism of PEO coating formation on AZ31 shows that the obtained coating consists of three layers: anodic film, outer and inner layers (Figures 6b, 9c).

However, if the PEO coating thickness exceeds $56 \mu \mathrm{m}$, the $5^{\text {th }}$ arc stage starts and coating defects appear. It is accompanied by short-term noise effects followed by sudden decrease in the voltage and increase in the current. Probably, it happens as a result of the anodic voltage value exceeding the value of gas-vapor phase breakdown voltage in one or more transversal pores. Their breakdowns are accompanied by high energy release, causing severe damage to the coating.

However, even if the treatment is stopped on the $4^{\text {th }}$ stage, the obtained corrosion resistance is not sufficient for long-term stand-alone corrosion resistance (Table 4).

Table 4. Time before the first visible pit appearance $\left(t_{\mathrm{p}}\right)$ during exposure of AZ31 alloy with and without PEO coatings in $3 \% \mathrm{NaCl}$ solution.

\begin{tabular}{cc}
\hline Coating thickness, $\boldsymbol{\mu m}$ & $\boldsymbol{t}_{\mathbf{p}}, \mathbf{h}$ \\
\hline 0 & $0.25 \pm 0.05$ \\
$18.2 \pm 2.3$ & $17.5 \pm 3.5$ \\
$43.9 \pm 3.5$ & $17 \pm 4.5$ \\
$53.0 \pm 6.9$ & $21 \pm 2$ \\
\hline
\end{tabular}

In order to increase the protective ability of the coatings it is possible to fill them with corrosion inhibitor using mainly the outer porous coating part as a land of microcontainers. 


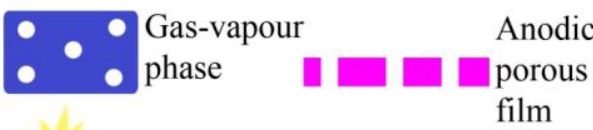

Faint microdischarges
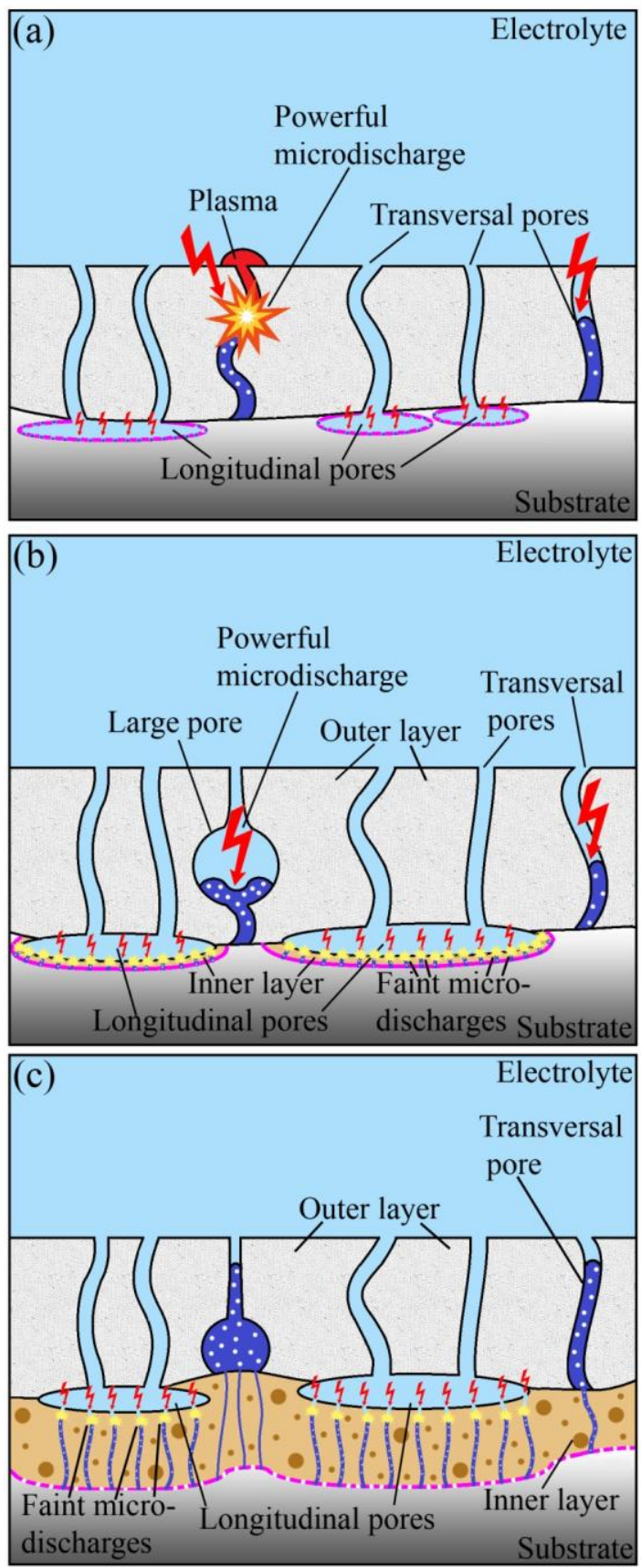

Figure 9. Mechanism of coating formation on AZ31 during PEO treatment in an alkalinephosphate-aluminate electrolyte when various types of microdischarges appear. 


\section{Corrosion testing of PEO coatings filled with sodium oleate}

To assess the effect of SOl on the protective ability of PEO coatings, they were impregnated for $10 \mathrm{~min}$ by $10 \mathrm{mM} \mathrm{SOl}$ solution and exposed to air for $24 \mathrm{~h}$. The thickness $(d)$ of the PEO coatings on AZ31 alloy was 20, 40 and $57 \mu \mathrm{m}$, respectively.

The polarization curves of AZ31 alloy with PEO coatings recorded in $0.3 \% \mathrm{NaCl}$ show that the resistance of the coatings increases slightly with increasing thickness, while the increase in protective ability is more pronounced on passage from 20 to $40 \mu \mathrm{m}$ (Figure 10). Infiltration by the SOl solution increased $E_{\text {ocp }}$ and the breakdown potential in all cases, which indicates an improvement in the corrosion resistance of PEO coatings.

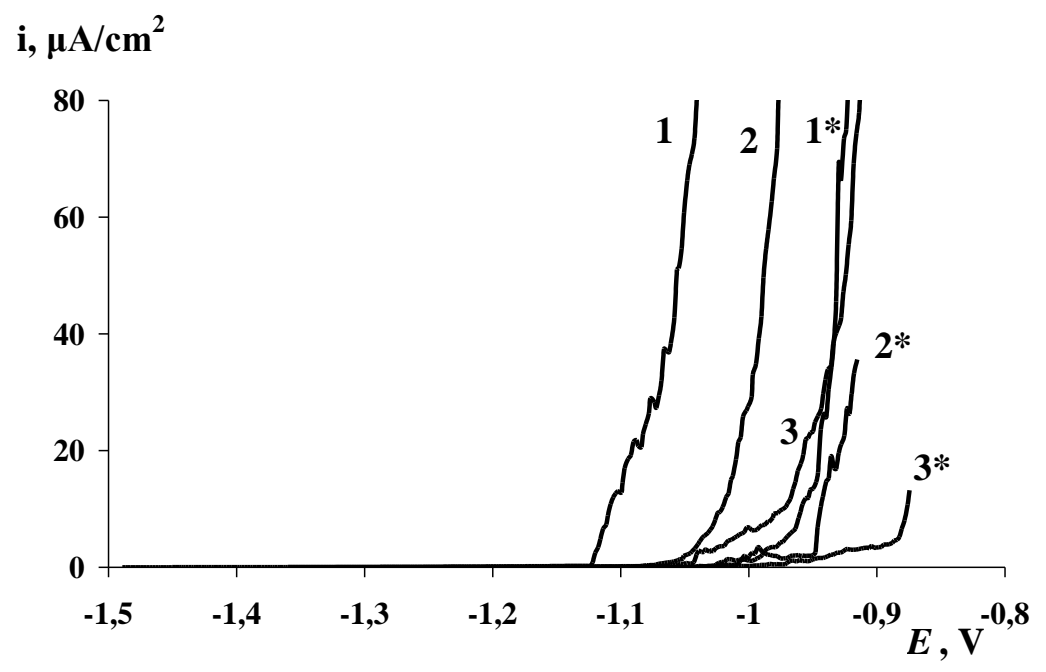

Figure 10. Anodic polarization curves of AZ31 alloy with three different PEO with $20\left(1,1^{*}\right)$, $40\left(2,2^{*}\right)$ and $55\left(3,3^{*}\right) \mu \mathrm{m}$ coatings thickness, without (1-3) and with infiltration of $10 \mathrm{mM}$ SOl solution.

The results of further corrosion test of coatings with a thickness of 20 and $40 \mu \mathrm{m}$ in a climate chamber and by SST are presented in Table 5. In a humid atmosphere, the coatings showed a high protective ability, however, for the sample with $d=20 \mu \mathrm{m}$ without filling by SOl, the first corrosion damage appeared after 2.5 months. Testing of the remaining samples continued until 5 months, but no signs of corrosion appear on them.

The effect of CI infiltration into PEO coatings is pronounced when PEO coatings are tested in SST. The first signs of corrosion on samples without CI impregnation appeared after $120 \mathrm{~h}$ with a PEO coating thickness of $20 \mu \mathrm{m}$ and $144 \mathrm{~h}$ for coating with $d=40 \mu \mathrm{m}$. The impregnation of coatings with SOl increased the time to corrosion damage by 3-4 days. After $720 \mathrm{~h}$ of testing numerous traces of corrosion products are observed on samples with PEO coatings without impregnation with SOl. They show localized areas with strong active corrosion. Samples with PEO coatings impregnated by CI also have signs of corrosion, but their intensity is much lower. Thus, on samples with a PEO coating 
containing SOl with $d=20 \mu \mathrm{m}$, corrosion is more common over the full area of the sample, but on samples with $d=40 \mu \mathrm{m}$ it appears only in form of small localized pits.

Table 5. Test results of samples with PEO coatings.

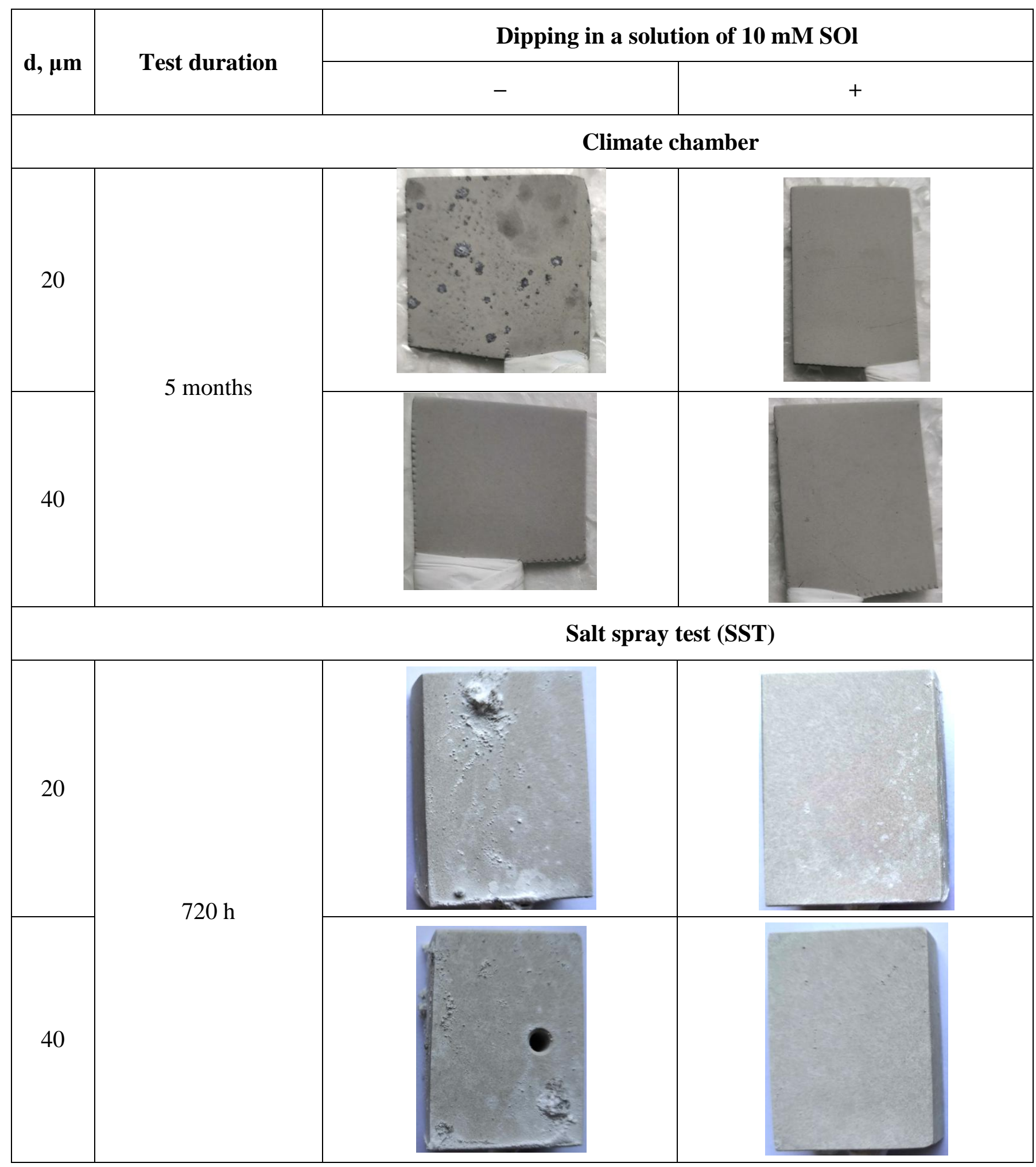




\section{Conclusions}

1. The mechanisms of three layered coating formation during PEO of AZ31 in alkali phosphate-aluminate electrolyte is proposed. Outer, anodic and inner layers are forming according to different mechanisms, involving: 1) ignition of powerful microdischarges in the vertical pores of the outer layer and in the spherical pores formed inside of it. A formation of a melted but porous layer is the result; 2) etching of magnesium, when the electrolyte reaches the metal substrate through the vertical pores, followed by anodizing of the substrate; 3) PEO microdischarges under the outer layer of the coating accompanied by deposition of the melted magnesium oxide in the inner layer.

2. It is revealed that the kinetics of linear coating growth changes because of the ignition of microdischarges under the outer layer of the coating and mainly growth of the inner layer of the coating.

3. Among the investigated 7 CIs and mixtures (SOl, SOS, SLin, sodium salt of SATC, 8$\mathrm{HQ}, \mathrm{SOl}+8-\mathrm{HQ}$, IFKhAN-25F), SOl showed the highest protective properties according to the results of polarization tests. Corrosion tests of AZ31 samples with preformed CI films in humid atmosphere also confirmed the effectiveness of SOl, therefore it was selected for impregnating PEO coatings.

4. Infiltration of PEO coatings in a solution of $10 \mathrm{mM} \mathrm{SOl}$ with subsequent drying of the samples in air can significantly increase their protective ability. Corrosion tests of such samples in a climate chamber showed that the filling effect is pronounced for thin PEO coatings $(20 \mu \mathrm{m})$, which, in the absence of CI impregnation, showed signs of corrosion even in a humid atmosphere. Under more corrosive conditions of SST, the SOl filling of PEO coatings increased the occurrence time of appearance of the first corrosion damages and significantly slowed down the onset of corrosion.

\section{Acknowledgements}

This work was financially supported by the RFBR (Project No. 18-53-76008) in the frame of the project ACTICOAT (Era.Net RUS Plus Call 2017, Project 477).

\section{References}

1. I.V. Suminov, P.N. Belkin, A.V. Epelfeld, V.B. Lyudin, B.L. Crete and A.M. Borisov, Plazmenno-elektroliticheskoe modifitsirovanie poverkhnosti metallov $i$ splavov (Plasma-electrolytic surface modification of metals and alloys), Tekhnosfera, Moscow, 2011, 2, p. 512 (in Russian).

2. A.G. Rakoch, A.V. Dub and A.A. Gladkova, Anodirovanie legkikh splavov pri razlichnykh elektricheskikh rezhimakh. Plazmenno-elektroliticheskaya nanotekhnologiya (Anodizing of light alloys in various electric modes. Plasma-electrolytic nanotechnology), Staraya Basmannaya, Moscow, 2012, p. 495 (in Russian). 
3. A.G. Rakoch, A.A. Gladkova and A.V. Dub, Plazmenno-elektroliticheskaya obrabotka aluminievykh $i$ titanovykh splavov (Plasma-electrolytic treatment of aluminum and titanium alloys), MISiS Publishing House, Moscow, 2017, p. 160 (in Russian).

4. L.A. Snezhko and V.S. Rudnev, Anodno-iskrovoe oksidirovanie magniya (Anodic Spark Oxidation of Magnesium), Tekhnika, Moscow, 2014, p. 160 (in Russian).

5. S.V. Gnedenkov, S.L. Sinebryukhov and V.I.Sergienko, Kompozitsionnye mnogofunktsional'nye pokrytiya na metallakh i splavakh, formiruemye plazmennoelektroliticheskim oksidirovaniem (Composite multifunctional coatings on metals and alloys formed by plasma-electrolytic oxidation), Dal'nauka, Vladivostok, 2013, p. 460 (in Russian).

6. Tu Wenbin, Ch. Yulin, W. Xinyao, Zh. Tingyan, H. Junxiang and Ch. Yingliang, Plasma electrolytic oxidation of AZ31 magnesium alloy in aluminate-tungstate electrolytes and coating formation mechanism, J. Alloy Compd., 2017, no. 725, 199-216.

7. M. Mohedano, R. Arrabal, B. Mingo, A. Pardo and E. Matykina, Role of particle type and concentration on characteristics of PEO coatings on AM50 magnesium alloy, Surf. Coat. Technol., 2018, 334, 328-335.

8. X. Lu, M. Mohedano, C. Blawert, E. Matykina, R. Arrabal, K.U. Kainer and M.L. Zheludkevich, Plasma electrolytic oxidation coatings with particle additions - a review, Surf. Coat. Technol., 2016, 307, 1165-1182.

9. D.V. Mashtalyar, S.V. Gnedenkov, S.L. Sinebryukhov, I.M. Imshinetskiy and A.V. Puz, Plasma electrolytic oxidation of the magnesium alloy MA8 in electrolytes containing TiN nanoparticles, J. Mater. Sci. Technol., 2017, 33, 461-468.

10. R. Arrabal, E. Matykina, F. Viejo, P. Skeldon, G.E. Thompson and M.C. Merino, AC plasma electrolytic oxidation of magnesium with zirconia nanoparticles, Appl. Surf. Sci., 2008, 254, 6937-6942.

11. K.M. Lee, K.R. Shin, S. Namgung, B. Yoo and D.H. Shin, Electrochemical response of $\mathrm{ZrO}_{2}$-incorporated oxide layer on AZ91 $\mathrm{Mg}$ alloy processed by plasma electrolytic oxidation, Surf. Coat. Technol., 2011, 205, 3779-3784.

12. K.M. Lee, B.U. Lee, S.I. Yoon, E.S. Lee, B. Yoo and D.H. Shin, Evaluation of plasma temperature during plasma oxidation processing of AZ91 Mg alloy through analysis of the melting behavior of incorporated particles, Electrochim. Acta, 2012, 67, 6-11.

13. M. Tang, H. Liu, W. Li and L. Zhu, Effect of zirconia sol in electrolyte on the characteristics of microarc oxidation coating on AZ91D magnesium, Mater. Lett., 2011, 65, 413-415.

14. S.V. Gnedenkov, S.L. Sinebryukhov, D.V. Mashtalyar, I.M. Imshinetskiy, A.S. Gnedenkov, A.V. Samokhin and Y.V. Tsvetkov, Protective composite coatings obtained by plasma electrolytic oxidation on magnesium alloy MA8, Vacuum, 2015, 120, $107-114$. 
15. T.S. Lim, H.S. Ryu and S.-H. Hong, Electrochemical corrosion properties of $\mathrm{CeO}_{2}-$ containing coatings on AZ31 magnesium alloys prepared by plasma electrolytic oxidation, Corros. Sci., 2012, 62, 104-111.

16. Y. Xiong, C. Lu, C. Wang and R. Song, The n-MAO/EPD bio-ceramic composite coating fabricated on ZK60 magnesium alloy using combined micro-arc oxidation with electrophoretic deposition, Appl. Surf. Sci., 2014, 322, 230-235.

17. M. Mohedano, C. Blawert and M.L. Zheludkevich, Silicate-based Plasma Electrolytic Oxidation (PEO) coatings with incorporated $\mathrm{CeO}_{2}$ particles on AM50 magnesium alloy, Mater. Design, 2015, 86, 735-744.

18. P.H. Sobrinho, Y. Savguira, Q. Ni and S.J. Thorpe, Statistical analysis of the voltagetime response produced during PEO coating of AZ31B magnesium alloy, Surf. Coat. Tech., 2017, 315, 530-545.

19. A. Gunterschulze and H. Betz, Electrolytic rectifying action, Z. Phys., 1932, 78, 196210.

20. A A. Gunterschulze and H. Betz, Elektroliticheskie kondensatory (Electrolytic capacitors), Oborongiz, Moscow, 1938, p. 200 (in Russian).

21. R.W. Revie and H.H. Uhlig, Corrosion and Corrosion Control. An Introduction to Corrosion Science and Engineering, John Wiley \& Sons, Inc., Canada, 2008, p. 513.

22. J. Hu, D. Zeng, Z. Zhang, T. Shi, G.-L. Song and X. Guo, 2-Hydroxy-4-methoxyacetophenone as an environment-friendly corrosion inhibitor for AZ91D magnesium alloy, Corros. Sci., 2013, 74, 35-43.

23. Q. Zong, L. Wang, W. Sun and G. Liu, Active deposition of bis (8-hydroxyquinoline) magnesium coating for enhanced corrosion resistance of AZ91D alloy, Corros. Sci., 2014, 89, 127-136.

24. X. Wang, L. Li, Z.-H. Xie and G. Yu, Duplex coating combining layered double hydroxide and 8-quinolinol layers on $\mathrm{Mg}$ alloy for corrosion protection, Electrochim. Acta, 2018, 283, 1845-1857.

25. A.S. Gnedenkov, S.L. Sinebryukhov, D.V. Mashtalyar and S.V. Gnedenkov, Protective properties of inhibitor-containing composite coatings on Mg alloy, Corros. Sci., 2016, 102, 348-354.

26. S.V. Lamaka, B. Vaghefinazari, Di Mei, R.P. Petrauskas, D. Höche and M.L. Zheludkevich, Comprehensive screening of Mg corrosion inhibitors, Corros. Sci., 128, 224-240.

27. J. Yang, C. Blawert, S.V. Lamaka, D. Snihirova, X. Lu, S. Di and M.L. Zheludkevich, Corrosion protection properties of inhibitor containing hybrid PEO-epoxy coating on magnesium, Corros. Sci., 2018, 140, 99-110.

28. T. Ishizaki, M. Okido, Y. Masuda, N. Saito and M. Sakamoto, Corrosion Resistant Performances of Alkanoic and Phosphonic Acids Derived Self-Assembled Monolayers on Magnesium Alloy AZ31 by Vapor-Phase Method, Langmuir, 2011, 27, 6009-6017. 
29. S. Szillies, P. Thissen, D. Tabatabai, F. Feil, W. Fürbeth, N. Fink and G. Grundmeier, Formation and stability of organic acid monolayers on magnesium alloy AZ31. The role of alkyl chain length and head group chemistry, Appl. Surf. Sci., 2013, 283, 339-347.

30. V.A. Ogorodnikova, Yu.I. Kuznetsov, A.A. Chirkunov and A.M. Semiletov, Inhibition of anodic dissolution of $\mathrm{Mg} 90$ alloy by adsorption layers of higher carboxylic acids, Int. J. Corros. Scale Inhib., 2018, 7, no. 2, 260-270. doi: 10.17675/2305-6894-2018-7$\underline{2-11}$

31. A.M. Semiletov, Yu.I. Kuznetsov and A.A. Chirkunov, Inhibition of Magnesium Corrosion by Salts of Higher Carbonic Acids, Prot. Met. Phys. Chem. Surf., 2017, 53, 1215-1220.

32. V.A. Ogorodnikova, Yu.I. Kuznetsov, N.P. Andreeva, A.Yu. Luchkin and A.A. Chirkunov, Adsorbtsiya anionov vysshikh carbonovykh kislot na magnii iz slaboshchelochnykh vodnykh rastvorov (Adsorption of higher carboxylic acid anions on magnesium from weakly alkaline aqueous solutions), Russ. J. Phys. Chem., 2019, Accepted manuscript (in Russian).

33. A.G. Rakoch, A.A. Gladkova, Z. Linn amd D.M. Strekalina, The evidence of cathodic micro-discharges during plasma electrolytic oxidation of light metallic alloys and micro-discharge intensity depending on $\mathrm{pH}$ of the electrolyte, Surf. Coat. Technol., 2015, 269, 138-144.

34. F. Zhu, J. Wang, S. Li and J. Zhang, Preparation and characterization of anodic films on AZ31B Mg alloy formed in the silicate electrolytes with ethylene glycol oligomers as additives, Appl. Surf. Sci., 2012, 258, no. 22, 8985-8990.

35. S. Yagi, A. Sengoku, K. Kubota and E. Matsubara, Surface modification of ACM522 magnesium alloy by plasma electrolytic oxidation in phosphate electrolyte, Corros. Sci., 2012, 57, 74-80.

36. M. Boinet, S. Verdier, S. Maximovitch and F. Dalard, Plasma electrolytic oxidation of AM60 magnesium alloy: Monitoring by acoustic emission technique. Electrochemical properties of coatings, Surf. Coat. Technol., 2005, 199, 141-149.

37. A.M. Kumar, S.H. Known, C.H. Jung, Y.H. Park, H.J. Kim and K.S. Shin, Fabrication and Electrochemical Corrosion Behavior of PEO Coatings on Strip-Cast AZ31Mg Alloy in 3.5\% NaCl Solution, Ind. Eng. Chem. Res., 2014, 53, 9703-9713.

38. J. Liang, B. Jiang, X. Gu, H. Zheng and C. Liu, Effect of severe shot peening on corrosion behavior of AZ31 and AZ91 magnesium alloys, J. Alloys Compd., 2019, 770, 500-506. doi: 10.1016/i.jallcom.2018.08.141

39. I.A. Kozlov, C.C. Vinogradov and S.A. Naprienko, Struktura i svoistva PEOpokrytiya, formiruemogo na splave ML5 v silikatno-fosfatnom elektrolite (The structure and properties of the PEO coating formed on ML5 alloy in a silicatephosphate electrolyte), Korroz.: mater., zashch. (Corrosion: materials, protection), 2017, no. 8, 37-48 (in Russian). 